\title{
El depósito de Pereiras Pequenas en Vila de Punhe, Viana do Castelo (norte de Portugal). Una revisión del contexto deposicional
}

The Pereiras Pequenas deposit in Vila de Punhe, Viana do Castelo (North of Portugal).

A review of the depositional context

\author{
Alexandre Manteiga Brea \\ Universidade do Minho ${ }^{1}$ \\ alex.manteiga@gmail.com
}

\section{Ana Maria Santos Bettencourt Universidade do Minho ${ }^{2}$}

\section{Beatriz Comendador Rey \\ Universidade de Vigo}

\section{Resumen}

El objeto de este trabajo es revisar las circunstancias de hallazơo de un conjunto de hachas de tope con dos aniIlas laterales y cono de fundición encontrado en la finca de Pereiras Pequenas/Rexio, lugar de Arque, parroquia de Vila de Punhe, municipio de Viana do Castelo, en 1916, mientras se realizaban labores agrícolas en unos viñedos. El hallazgo fue dado a conocer por Serpa Pinto (1928, 1933a, 1933b), aunque la noticia del descubrimento fue publicada años más tarde por Viana (1938). Este conjunto formado por más de cien ejemplares, constituye uno de los depósitos monotipológicos más numerosos de la Península Ibérica. A partir de su contexto espacial se ofrecen algunas interpretaciones sobre la localización de ésta y otras deposiciones similares en el Noroeste de la Península Ibérica.

\section{Palabras clave}

Depósitos monotipológicos, Hachas de tope con dos anillas laterales y cono de fundición, Contexto deposicional, Interpretaciones.

\begin{abstract}
The aim of this work is to review the discovery of a group of double looped palstaves with casting jets found on the Pereiras Pequenas/Rexio estate, Arque, parish of Vila de Punhe in 1916, while doing agricultural works in a vineyard. The hoard was acknowledged by Rui de Serpa Pinto (1928, 1933a, 1933b), although the discovery circumstances were published years later by Viana (1938). This assemblage formed by more than one hundred objects, constitutes one of the more numerous single type hoards of the Iberian Peninsula. Some interpretations are given, considering the context location of this hoard, and other similar deposits in the Northwest of Iberia.
\end{abstract}

\section{Keywords}

Single type hoards, Double looped palstaves with jets, Depositional context, Interpretations.

\footnotetext{
Data de envío: 25-11-2014 Data de aceptación: 20-01-2015
}

1 Estudiante de Doctorado de la Universidade do Minho. Laboratório de Paisagens, Património e Território (Lab2 PT). E-mail: alex.manteiga@gmail.com.

2 Departamento de História da Universidade do Minho, Campus de Gualtar, 4710-057 Braga (Portugal); Laboratório de Paisagens, Património e Território (Lab2 PT). Email: anabett@uaum.uminho.pt.

3 Facultad de Historia, Universidade de Vigo (España); Miembro del Grupo de Estudio de Arqueología, Antigüedad y Territorio GEAAT. E-mail: beacomendador@uvigo.es. 


\section{INTRODUCCIÓN}

Este trabajo se inscribe en un programa de contextualización, física y ambiental, de revisión de los contextos y circunstancias de hallazgos metálicos de la Edad del Bronce en la fachada litoral del noroeste peninsular, desde la cuenca del Vouga, en el Centro-Norte de Portugal, hasta la cuenca del Ulla, en A Coruña, Galiza, dentro del área de estudio del proyecto de tesis doctoral titulado "Depósitos de la Edad del Bronce de la Fachada Occidental del Noroeste de Iberia entre las Cuencas del Vouga y del Ulla: Contextos e Interpretaciones".

Con este trabajo pretendemos revisar el contexto físico, de deposición, y las circunstancias de descubrimiento de un conjunto formado por más de cien hachas de dos anillas con cono de fundición, pertenecientes al Bronce Final, conocido tradicionalmente como el depósito de Vila de Punhe. La noticia del descubrimiento fue publicada en 1938, por Tomás Simões Viana, aunque Rui de Serpa Pinto ya había mencionado anteriormente el hallazgo, si bien lo adscribe erróneamente a la "freguesia" 4 de Vila Fria, vecina de Vila de Punhe. No obstante, Pinto informa que los examinó “... no Museu de Viana do Castelo e na colecção do Sr. Serafim Neves” (PINTO 1928:195; 1933a, 1933b).

En nuestra visita al lugar del hallazgo contamos con las informaciones proporcionadas por el Sr. José Gonçalo Meira Alves, natural de Arques y por el Padre Alípio Rodrigues Torres, párroco de Vila de Punhe que nos permitieron localizar el contexto físico del lugar de hallazgo, ciertamente importante para su interpretación.

\section{CONTEXTO ADMinisTRATIVo Y Físico}

La zona donde apareció este conjunto se corresponde con la antigua finca de Pereiras Pequenas, en el lugar de Arques, "freguesia" de Vila de Punhe, municipio de Viana do Castelo. Las coordenadas geográficas decimales, en el sistema WGS 84 son: N 41,659966; W -8,726937, Alt. 108 m (Fig. 1).

La finca conocida, en los inicios del s. XX, como Pereiras Pequenas se encuentra en un lugar hoy designado como Rexio, microtopónimo relacionado con nieblas, muy frecuentes en esta zona. Se sitúa en una pequeña plataforma en ligera pendiente al lado de la fuente de Bomfim (a pocas decenas de metros hacia el este, y con agua todo el año) rodeada de montes al norte, este y noroeste, aunque con un buen campo visual al oeste y al sur, hacia el valle del Neiva. En dirección norte se distingue una pequeña elevación natural conocida como el Alto do Coturinho, la cual continúa hacia el Alto de Roques, en el que tienen su origen varios cursos de agua afluentes de la margen derecha del Neiva (Fig. 2).

4 División administrativa portuguesa similar a las parroquias en España, sin embargó las "freguesias" son autónomas del poder religioso y se benefician de autonomía política, teniendo óroganos de gestión pública y administrativa. Su autonomía está ligada al hecho de que Portugal constituye una República. 


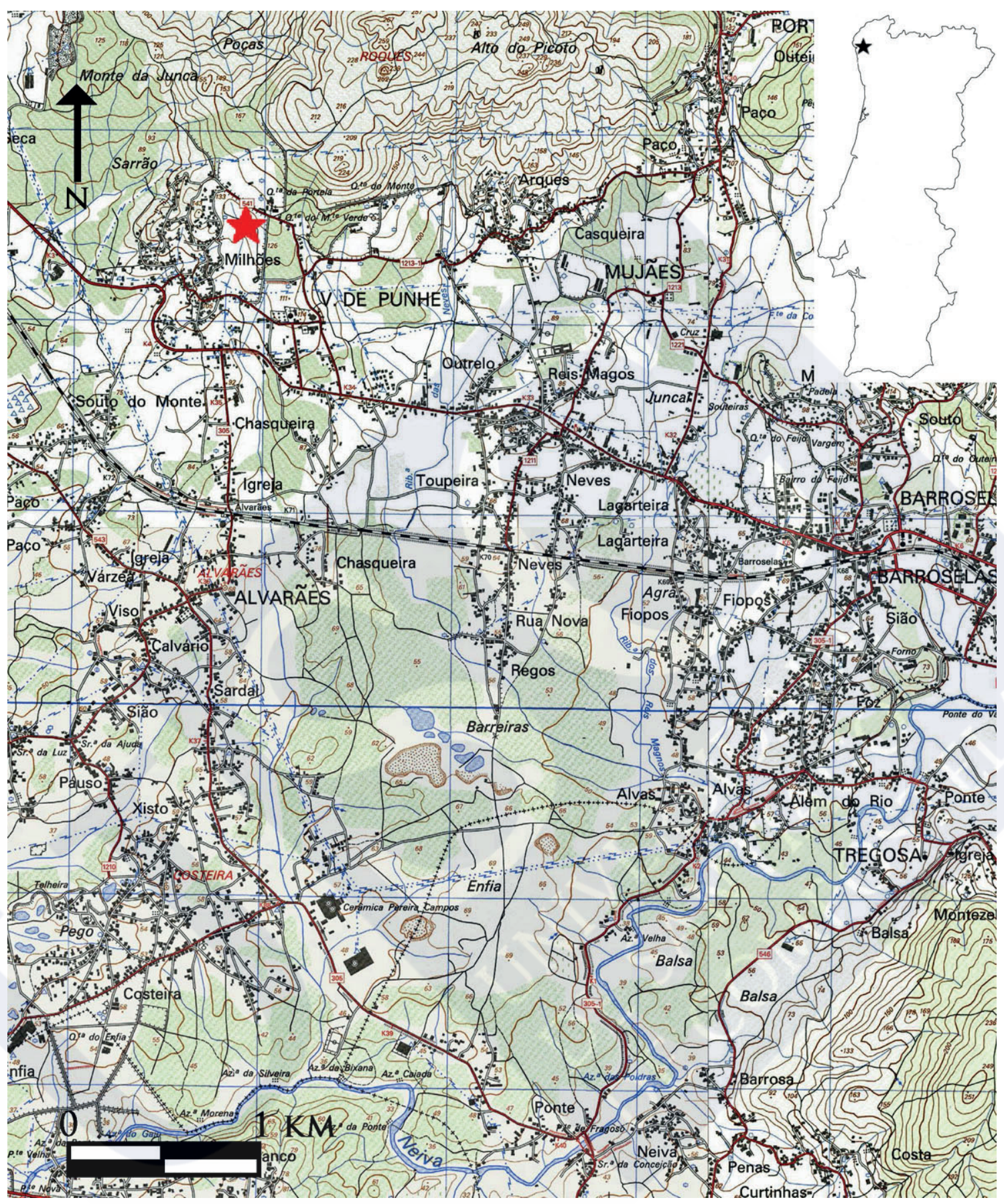

Figura 1. Localización aproximada del depósito de Pereiras Pequenas/Rexio (situación en la Carta Militar de Portugal, esc. 1/25.000, hoja no. 40).

Esta zona es atravesada por el Ribeiro de Agra, tributario del Neiva, con orientación norte-sur, y por el Regato do Feital con una alineación este-oeste, que constituye una de las fuentes del Ribeiro do Rexio (TORRES 2001: 85), también conocido como el Rego das Neves. En nuestra visita al lugar, se procedió a la contextualización de este depósito, en la que pudimos comprobar que el terreno donde apareció se corresponde con un área agrícola, con tierras arenosas, al lado del camino oficial que lleva a la Vía Real, o de la vía romana "per loca marítima" que pasaría por sus inmediaciones (ABREU y ALMEIDA 1988). El depósito se encuentra en una zona tradicional de paso, que de sur 
a norte, permite la comunicación de las cuencas del Neiva y del Lima, aunque también constituye una encrucijada en la que se cruzan muchos caminos hacia el litoral y hacia el interior.

Según la Carta Geológica de Portugal, esc. 1/50 ooo, no 5A (TEIXEIRA et al. 1972) el substrato geológico del lugar se corresponde con rocas silúricas metamorfizadas, especialmente corneanas, xistos andaluzíticos, granatíferos, luzentes, etc, en las proximidades de aluviones (Fig. 3). En relación con los recursos mineros del valle del Neiva, existen noticias de exploraciones de plata y antimonio en el Monte de S. Simão, en la "freguesia" de Cossourado (AZEVEDO 1897: 234), hacia el este del lugar de hallazgo. Ocurren igualmente formaciones áureo-argentíferas en las "freguesias" de Portela das Cabras, Sobradelo y Duas Igrejas, municipio de Vila Verde, en filones cuarzosos de reducido espesor, orientados de nordeste hacia sudoeste (TEIXEIRA et al. 1975) y en áreas con cursos de agua que discurren hacia el Neiva. El estaño existe en la vertiente noroeste de la sierra da Padela y en la sierra da Nó, donde también nacen varios cursos de agua que alimentan el Neiva por su ribera norte.

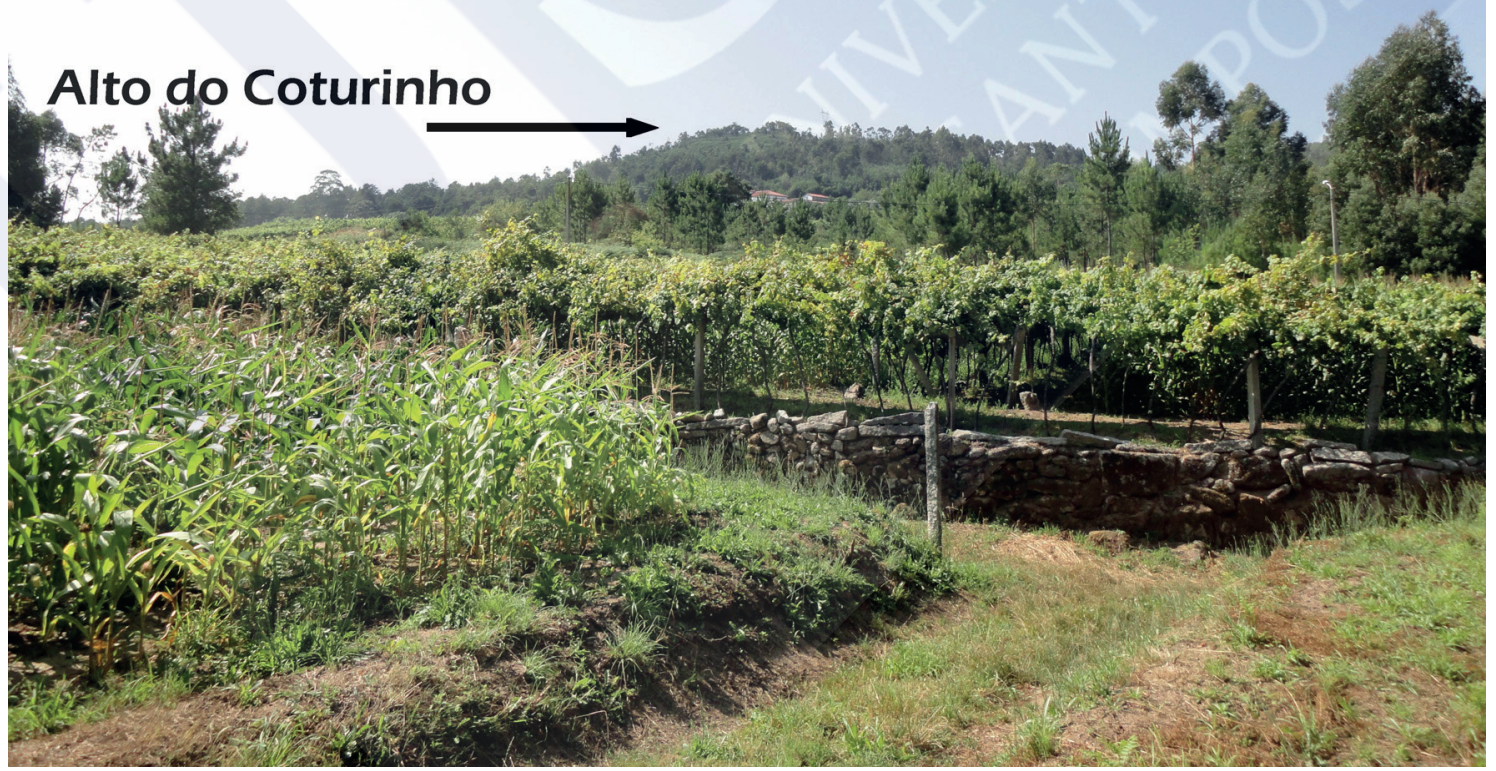

Figura 2. Finca de Pereiras Pequenas/Rexio (Información proporcionada por el Padre Alípio Rodrigues Torres).

Además existen numerosos vestigios arqueológicos de exploraciones a cielo abierto en Marrancos, en el Monte do Lousado y en la sierra da Nó de exploraciones de estaño (VIEIRA 1886; REIS 1978), entre otras situadas hacia el oeste de los Montes do Cossourado, de Arefe y de Roques (MACIEL 2003). 


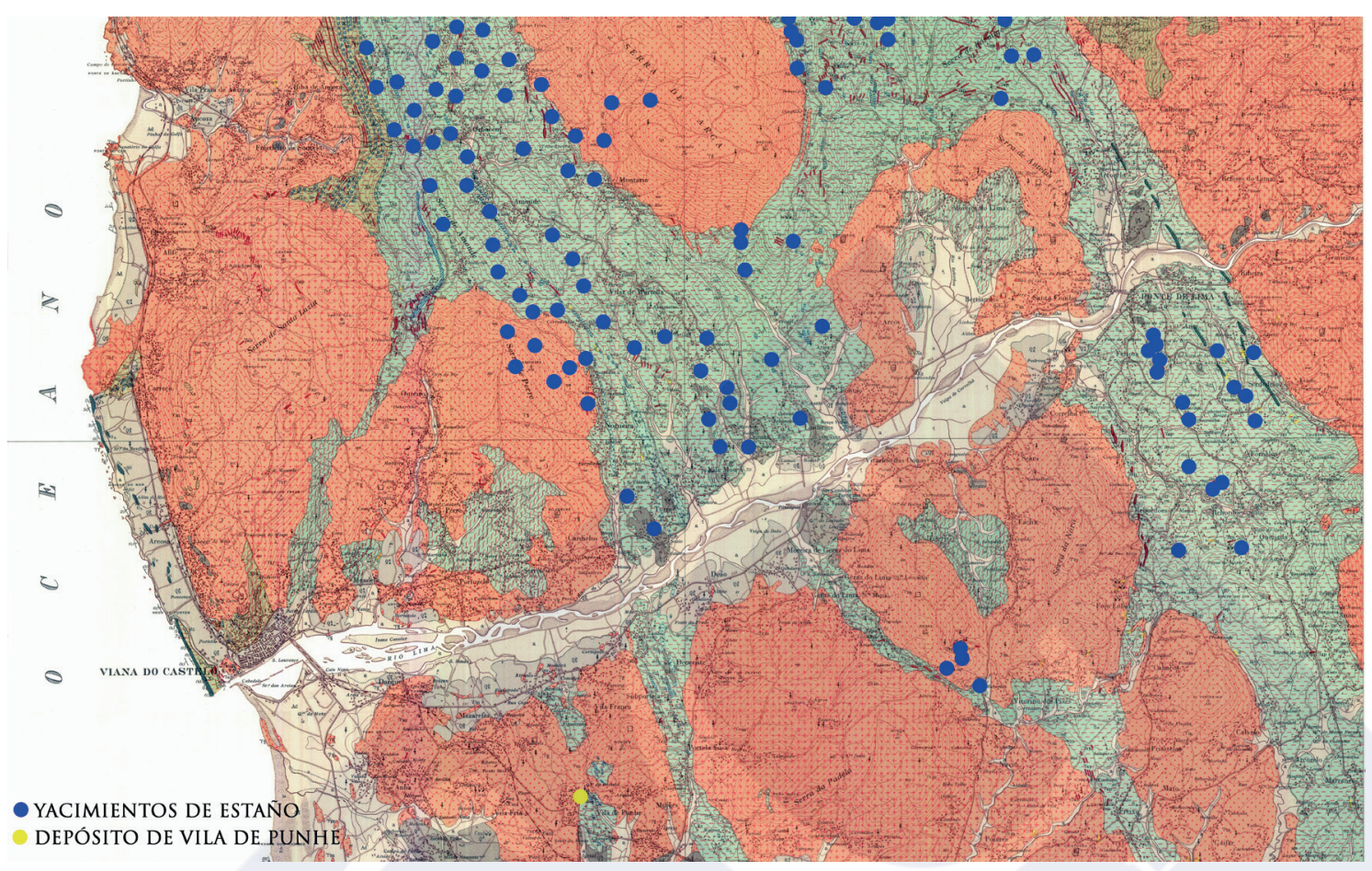

Figura 3. Distribución de las explotaciones de estaño (en uso, desuso o con ocurrencias de estaño) con respecto a la localización del depósito de Pereiras Pequenas, Vila de Punhe (situación en la Carta Geológica de Portugal, 1/50.000, hoja no. 5-A) (TEIXEIRA et al. 1972).

Hay que resaltar que si bien el depósito de Pereiras Pequenas no se encuentra inmerso en una zona rica en recursos mineros de casiterita, las explotaciones más cercanas se sitúan a escasos 7 km al norte en Torre, y a menos de 9 km al noreste en Reborido (Fig. 3).

\section{Circunstancias del Descubrimiento}

El primero en dar noticia de este descubrimiento es R. Serpa Pinto (1928: 195), "Esconderijos de fundidores não são raros no Minho, podendo-se citar entre outros, em ... Vilafria (Darque)", F. López Cuevillas y F. Bouza Brey (1929: 68) también recogen este hallazgo, aunque al igual que R. Serpa Pinto lo adscriben erróneamente a la "freguesía" de Vilafría, vecina a la de Vila de Punhe, "Vilafría, Viana do Castello, Portugal.- No Museu de Viana hai 14 machados de talón de dous aneis, procedentes de un acobillo de aquil termo, 4 alcóntranse na coleizón Sousa Neves da mesma vila de Viana e algún outro hai no Museu Ethnológico Portugués”. No obstante, las circunstancias del descubrimiento de este depósito son referidas por Viana (1938: 7) de la manera siguiente: "Em 1916, quando se procedia à abertura duma vala para plantação de vinhedo, numa propriedade sita no lugar das Pereiras-Pequenas - freguesia de Vila-de-Punhe, concelho de Viana-do-Castelo, - foi encontrada à profundidade aproximada de om, 80 uma grande quantidade de machados de bronze. Como quási sempre acontece, logo que se soube do achado, começou circulando o boato - entre os moradores da freguesia, - de que, no lugar das Pereiras-Pequenas se havia encontrado um tesouro, constituído por castiçais de prata, aventando outros, o aparecimento de grossas barras de ouro. $O$ 
dono da propriedade, Snr. Agostino Nascimento dos Santos, informado do aparecimento do tesouro ordenou a sua imediata remoção para Viana-do-Castelo, não sem que, - segundo nos informam, - alguns machados tivessem sido desviados. Conduzidos para Viana, e observados apenas sob o ponto de vista da qualidade do metal, logo do espírito do avaro e ignorante dono da propriedade, se desvaneceu a ideia de se tratar do precioso vil metal. Pesaroso e desiludido, fez então remover para uma oficina de metalurgia a maior parte desses utensílios, tendo, antecipadamente, feito arrancar de todos, o chumbo que continham os cabeços de fundição”.

\section{Características de los obJetos}

El hallazgo estaba compuesto por más de 100 hachas de talón con dos anillas, con diferentes dimensiones, y con pesos que variaban entre los 600 y 700 gr (VIANA 1938). Desgraciadamente la mayor parte de las hachas que componían este conjunto fueron fundidas al poco de su descubrimiento, tal y como refiere Viana (1938: 7) "a maior quantidade tinha sido já fundida e aplicada na manufactura dum cilindro, cujo pêso atingiría 60 quilogramas". Sabemos por el mismo autor, que un número indeterminado de hachas se quedaron en manos de su descubridor, otras fueron salvadas del infortunio por el señor Jacinto José Alves, propietario

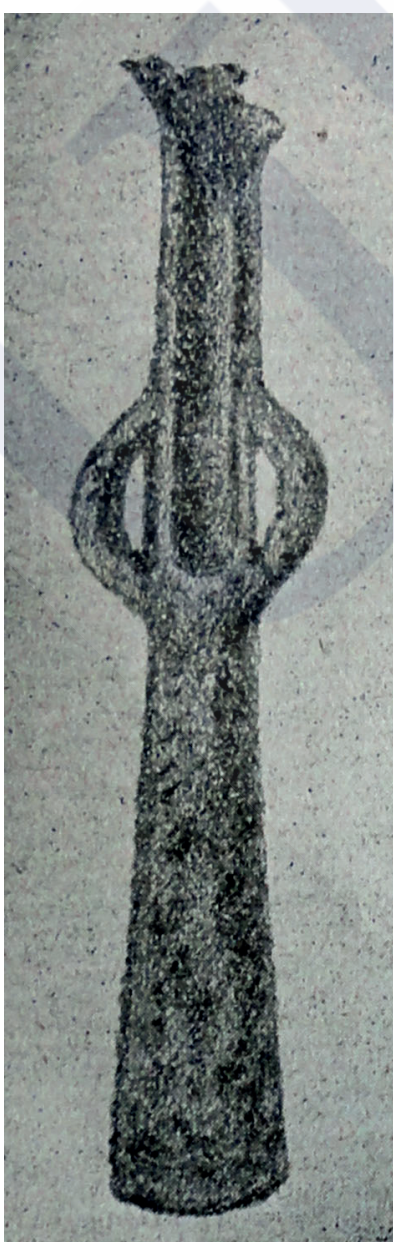

Figura 4. Hacha del conjunto de Vila de Punhe (VIANA 1938: 8). de la fundición que cedió una a Tomás Simões Viana, otro ejemplar fue entregado a un amigo de Tomás Simões Viana, con $220 \mathrm{~mm}$ de largo y $46 \mathrm{~mm}$ de filo, y finalmente uno o más ejemplares pasaron a manos de Serafim Neves que los integró en su colección y cedió algunos al Museo Dr. Leite de Vasconcelos (Museo Nacional de Arqueologia en Lisboa) (VIANA 1938: 7-8).

Viana (1938: 7), reprodujo una de las hachas pertenecientes a este conjunto, correspondiente a un hacha de tope con dos anillas laterales y cono de fundición, este último en estado incompleto, con $200 \mathrm{~mm}$ hasta el límite de la cabeza y 35 $\mathrm{mm}$ de filo (Fig. 4).

Monteagudo (1977: 167) dibujó otra hacha de la colección de Simões Viana, la cual dice estar en la farmacia del propietario. Se trata del ejemplar no. 997. El hacha se encuentra en estado completo y presenta sus dos caras planas. En esta pieza se advierten las rebabas de fundición, y se encuentra el cono de fundición en estado completo. Tiene una sección casi rectangular, bordes ligeramente redondeados y filo plano. Tenía $239 \mathrm{~mm}$ de largo, por $47 \mathrm{~mm}$ de filo y $25 \mathrm{~mm}$ de espesor (Fig. 5).

En esta obra, Monteagudo dibuja y describe una tercera hacha perteneciente a este depósito que estaría en la colec- 
ción de Serafim de Sousa Neves, o en el Museo Regional de Viana do Castelo, según la citación de Pinto (1928: 192) ${ }^{5}$. Se trata de la pieza no. 1096, que muestra dos acanaladuras verticales que comienzan justo por debajo de la zona de enmangue y discurren casi en paralelo hasta el filo. El cono de fundición solo se conserva de forma parcial. La sección es similar a la del hacha anterior, si bien esta última tiene los bordes casi paralelos y el filo es ligeramente curvado. Tenía $209 \mathrm{~mm}$ de largo, por $34 \mathrm{~mm}$ de filo y $25 \mathrm{~mm}$ de espesor (Fig. 5).

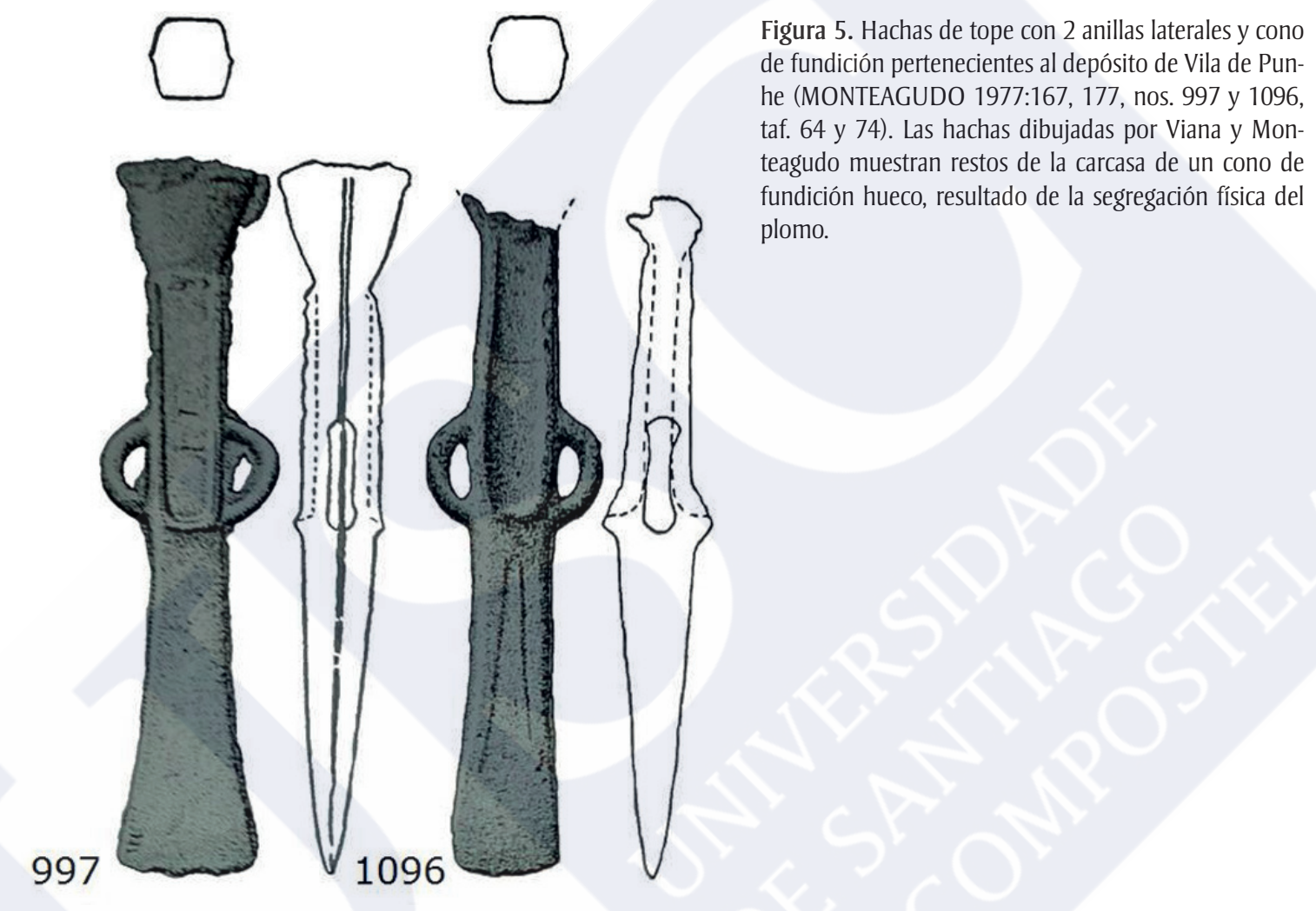

Años más tarde, Maciel (2003) observó dos hachas en propiedad de un sobrino de Tomás Simões, de nombre Gaspar Simões Viana, natural de Vila de Punhe, que las habría heredado de su tío, como pertenecientes al depósito de Pereiras Pequenas. Este autor dibuja y fotografía un hacha que nos parece ser la misma dibujada por Viana, en 1938, aunque se confunda en las dimensiones del filo en cerca de $9 \mathrm{~mm}$. Creemos que habría querido decir $34 \mathrm{~mm}$ y no $44 \mathrm{~mm}$. Especialmente si tenemos en cuenta que la primera medida está de acuerdo con el dibujo reproducido por él. Sobre este hacha también refiere el peso que es de 655,8 gr. Fue designada por nosotros como el hacha no. 1 (Fig. 6, Tab. 1).

$5 \quad$ Hay que destacar que el escultor Serafim de Sousa Neves fue fundador del Museo Regional de Viana do Castelo. Es posible que esta hacha, aún esté en el Museo de Artes Decorativas de Viana o en el Gabinete de Arqueologia de la Câmara Municipal de Barcelos, donde se encuentran diversas hachas muy fragmentadas debido a su avanzado estado de corrosión, y hachas sin cono de fundición que podrían formar parte de este depósito. 

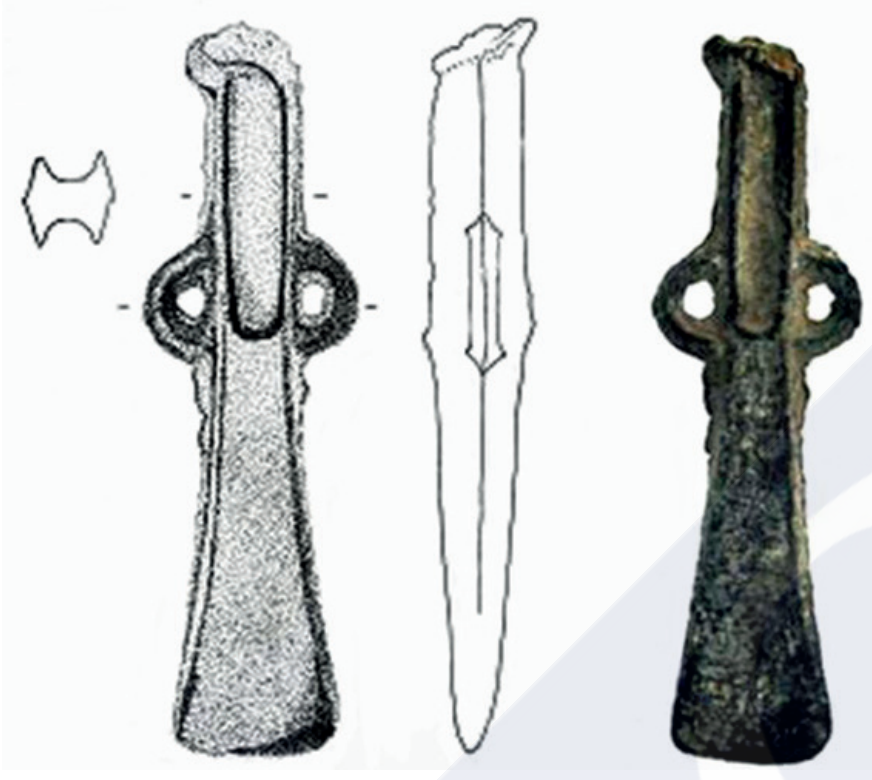

Figura 6. Hacha del depósito de Pereiras Pequenas de la colección particular de Gaspar Simões Viana (MACIEL 2003), que se corresponderá con la publicada por Viana (1938).

En cuanto al hacha que designamos como no. 2, Maciel (2003: 73) no la fotografía ni dibuja, y considera que podría haber sido una donación que el amigo de Simões Viana le habría hecho. En verdad, por las dimensiones que presenta y por la descripción que efectúa, nos parece que se corresponde con el hacha ya dibujada por Monteagudo (1977) con el número 997. Según Maciel, "Este segundo exemplar, bem maior que o anterior, mantém o cabeço de fundição e as asas, de secção circular, apresentam rebarbas interiores. Talvez devido a deficiente ajuste das valvas do molde, as faces do machado não são simétricas. À semelhança do primeiro, este instrumento apresenta uma pátinea verde-escura. O gume está embotado, não pelo uso, de que não apresenta sinais, maspelo fabrico deficiente" (Idem: 73). Mide de largo $240 \mathrm{~mm}$, por $48 \mathrm{~mm}$ en el filo y 30 mm de espesor, pesando 1154,3 gr (Tab. 1). Las diferencias de milímetros en relación con las dimensiones de Monteagudo (1977:167) podrían deberse al uso de instrumentos de mayor precisión por parte del último autor.

En síntesis, del vasto depósito de Pereiras Pequenas apenas se conocen tres hachas, todas ellas de talón con dos anillas, aunque con formas, dimensiones, y pesos distintos, que pueden variar entre los 655,8 gr y los 1154,3 gr. Todas estas hachas tenían cono de fundición, si bien, no todas presentaban nervaduras en su lámina. También el filo se presenta de distinta forma siendo, por veces, más curvo o más rectilíneo. Según el documento gráfico conservado, una de las hachas muestra restos de la carcasa de un cono de fundición hueco, lo que podría deberse a la segregación física del plomo.

En cuanto a la diferencia de pesos entre las distintas piezas aquí expuestas, nos remitiremos a la siguiente cita de Viana (1938: 7), "por êste pormenor, poderemos avaliar da quantidade dos machados encontrados no esconderijo de Vila-de-Punhe, atendendo a que o pêso de cada um, oscilava entre 600 a 700 gramas, -desprovidos do chumbo que continham os cabeços de fundição", de lo que se infiere que Viana hace una estimación de la cantidad de objetos que compondrían este depósito en base al peso estimado de las piezas conservadas, las cuales desprovistas de los conos de fundición, tenían un peso de entre 600 a 700 gr. Como ya hemos sugerido Viana no hace directamente estas medi- 
ciones, tal y como refiere (1938: 7), "Um feliz acaso levou a essa oficina o Snr. Jacinto José Alves, o qual, verificando da importância de tais objectos, evitou que os poucos ali ainda existentes, fôssem destruídos”. Por lo tanto las diferencias observadas en cuanto al peso de las hachas aquí estudiadas probablemente se debe al hecho de que todavía conservan los conos de fundición.

Tabla 1. Características de las hachas en estudio.

\begin{tabular}{|c|c|c|c|c|c|c|c|}
\hline OBJETO & $\begin{array}{l}\text { LONG. } \\
\text { TOTAL }\end{array}$ & $\begin{array}{l}\text { ANCHO } \\
\text { (ASAS) }\end{array}$ & $\begin{array}{l}\text { ANCHO } \\
\text { (FILO) }\end{array}$ & GROSOR & PESO & REFERENCIA & DEPÓSITO \\
\hline $\begin{array}{c}\text { Hacha de } \\
\text { Viana (1938) }\end{array}$ & $200 \mathrm{~mm}$ & - & $35 \mathrm{~mm}$ & & $600-700 \mathrm{gr}$ & Viana (1938) & $\begin{array}{l}\text { Colección privada de Simões } \\
\text { Viana, existente en su Farmacia. }\end{array}$ \\
\hline $\begin{array}{l}\text { Hacha de tope } \\
\quad(\text { no. } 1)^{6}\end{array}$ & $198 \mathrm{~mm}$ & 56 & $44(i)$ & 29 & $655,8 \mathrm{gr}$ & $\begin{array}{l}\text { MACIEL 2003: } \\
73\end{array}$ & $\begin{array}{l}\text { Colección particular de Gaspar } \\
\text { Simões Viana, sobrino de Simões } \\
\text { Viana. }\end{array}$ \\
\hline Hacha 997 & $238 \mathrm{~mm}$ & - & 47 & 25 & - & $\begin{array}{l}\text { MONTEAGUDO } \\
\text { 1977: } 167 ; \\
\text { SIMÕES } 1938\end{array}$ & $\begin{array}{l}\text { Colección privada de Simões Via- } \\
\text { na, hasta los años } 70 .\end{array}$ \\
\hline $\begin{array}{l}\text { Hacha de tope } \\
\quad(\text { no. } 2)^{7}\end{array}$ & $240 \mathrm{~mm}$ & 60 & 48 & 30 & $1154,3 \mathrm{gr}$ & MACIEL 2003:73 & $\begin{array}{l}\text { Colección particular de Gaspar } \\
\text { Simões Viana, sobrino de Simões } \\
\text { Viana }{ }^{8} \text {. }\end{array}$ \\
\hline Hacha 1096 & $209 \mathrm{~mm}$ & & 34 & 25 & - & $\begin{array}{l}\text { MONTEAGUDO } \\
\text { 1977: } 177 ; \\
\text { PINTO } 1928\end{array}$ & $\begin{array}{l}\text { Colección de Serafim Neves o } \\
\text { Museo de Viana, hasta los años } \\
70^{\circ} \text {. }\end{array}$ \\
\hline
\end{tabular}

A pesar de estos datos es necesario referir que el propietario, antes de fundir gran parte de las hachas, les sacó “o chumbo que continham os cabeço de fundição" (VIANA 1938: 7). Algunos ejemplares de hachas de tope, fabricados con aleación ternaria y altos contenidos en plomo, presentan, un fenómeno de segregación por el que el plomo forma una bola o esfera en el interior del cono de fundición y se separa físicamente del bronce, que queda rodeándolo formando una carcasa. Puede observarse en ejemplares de otros depósitos del noroeste peninsular, como el de A Mazaeda (San Pedro de Neiro, Fonsagrada) (VÁZQUEZ SEIJAS 1953; MONTEAGUDO, 1977: 168-169), o en los del interesante conjunto inédito de procedencia desconocida, depositado en 1997 el Museo Arqueológico de A Coruña (no. Cat. 3902/1-151, objetos de bronce, fotografías) (Fig. 7). Este fenómeno ha sido explicado desde el punto de vista teórico mediante el diagrama de fases $\mathrm{Cu}-\mathrm{Pb}$ (ROVIRA \& GÓMEZ 2003: 20-21), en el contexto de la metalurgia de bronces altamente plomados del noroeste peninsular (MONTERO et al., 2003). Además, podría deberse a que durante el proceso de vertido en el molde, la parte enriquecida en plomo se iría al fondo del crisol, por lo que se vertería al molde el caldo más plomado al final (Com. Pers. SALVADOR ROVIRA), así como por los distintos comportamientos en el proceso de solidificación.

6 Será la misma hacha publicada por Viana (1938).

7 Será la misma hacha publicada por Monteagudo con el no. 997.

8 Maciel (2003:73) supone que esta hacha será la que Viana (1938) dice que quedó en posesión de un amigo cuyo nombre no indica.

9 Es posible que aún esté en el Museo de Artes Decorativas de Viana o en el Gabinete de Arqueologia de la Câmara Municipal de Barcelos donde están las hachas muy fragmentadas o en estado avanzado de corrosión. 


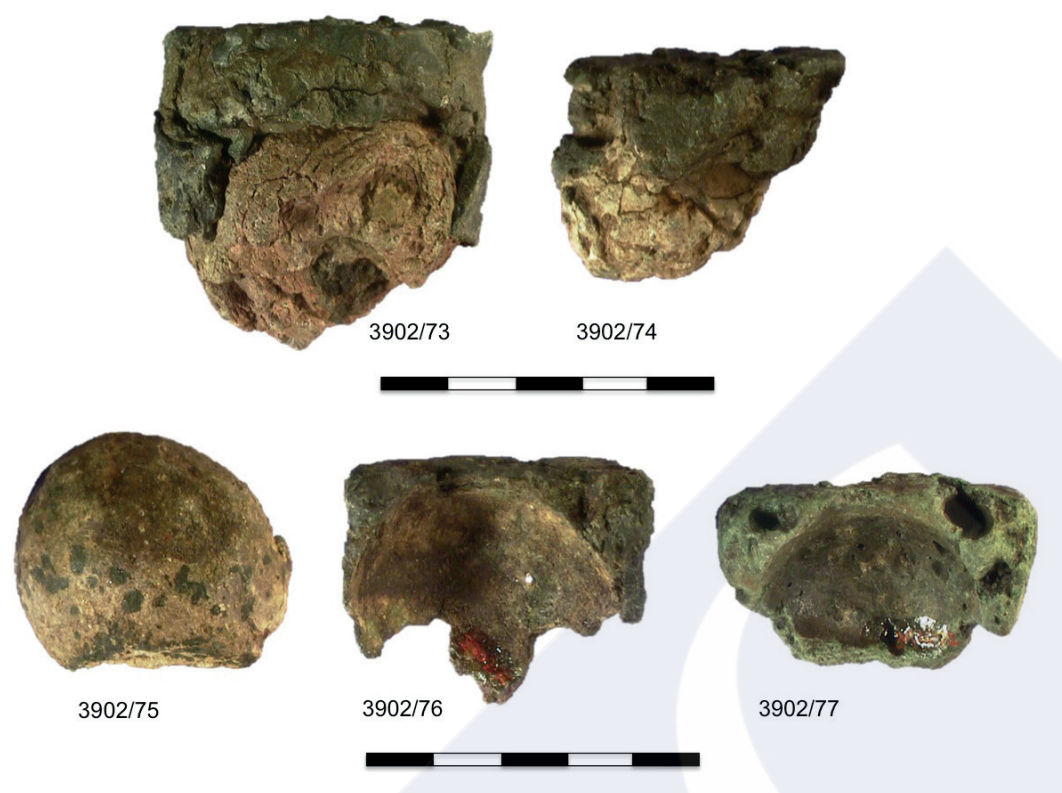

Figura 7. Conos de fundición con segregación física del plomo y carcasas huecas pertenecientes al conjunto de bronces del Museo Arqueolóxico e Histórico de A Coruña (no. Cat. 3902/73, 74, 75, 76, 77).

Así pues, en el caso que citamos, podemos entender que los ejemplares de Pereiras Pequenas tenían un alto contenido en plomo, por lo que extrajeron la esfera segregada de plomo en el cono, y dejaron el resto de la carcasa débil enriquecida en cobre y estaño, que se rompería en pequeños fragmentos por su fragilidad, lo que parece mostrar el dibujo de alguna de las hachas, donde se ven restos de carcasa hueca y aparece rota la zona del cono de fundición.

Curiosamente, en depósito en el Museo de Artes Decorativas de Viana do Castelo (Antiguo Museo Regional de Viana do Castelo), encontramos, en la caja 5, una bolsa de plástico que contenía un conjunto de 28 fragmentos de carcasa de cono de fundición, 1 fragmento de filo, 1 fragmento de cono-tope y 1 fragmento de tope-anillas, todos con abundantes cloruros y previsible alto contenido en plomo (COMENDADOR REY et al. 2013). Por sus características, podría formar parte del conjunto de hachas de anillas del depósito de Pereiras Pequenas que estudiamos el año anterior en la Casa dos Nichos (Fig. 8).

Consideramos, igualmente, la posibilidad de que algunas de las hachas hoy expuestas en la Casa dos Nichos, en Viana do Castelo, también puedan pertenecer a este depósito (Fig. 9), ya bien porque se les habrían retirado las cabezas de plomo, ya bien por sus pátinas, semejantes a la que describe Simões Viana (1938: 8). Según su descripción, las hachas del conjunto presentaban una pátina verde oscura con incrustación de una capa blanca carbonatada que podría resultar de la presencia de plomo, cuyos productos de corrosión suelen ser blancos (COMENDADOR REY et al. 2013).

Las dos hachas muestran en mayor o menor medida evidencias del proceso de fundición, con rebabas y conos de fundición visibles en ambos ejemplares, lo cual demuestra que nunca fueron utilizadas con finalidad práctica. El hacha ${ }^{0} 997$ tiene el filo embotado y, según Maciel (2003: 73), presenta burbujas y vacuolas.

El hacha no. 1096 muestra vacuolas y poros de fundición en su superficie, lo que evidencia un acabado defectuoso. 

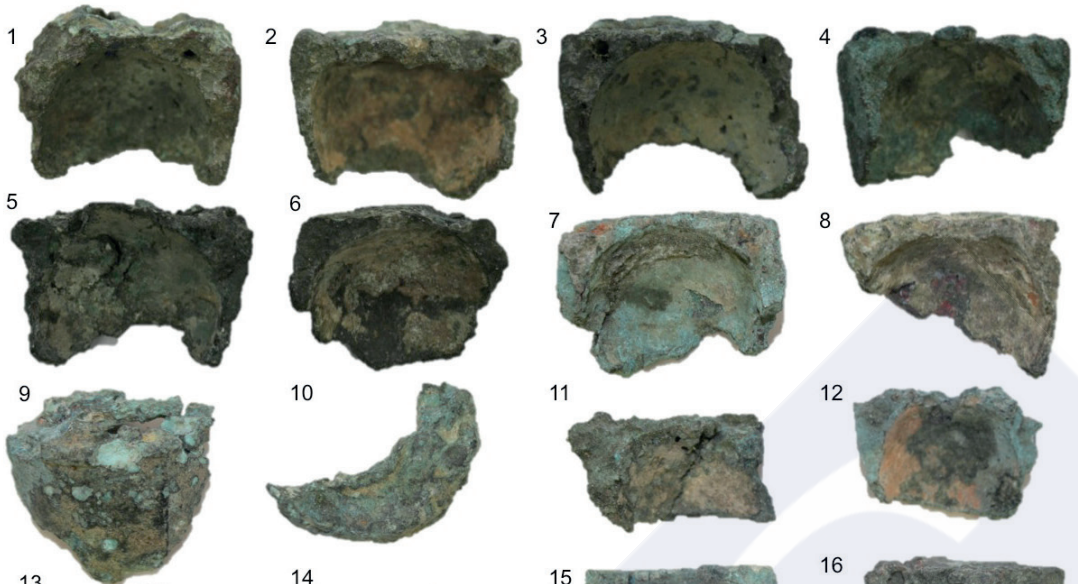

11
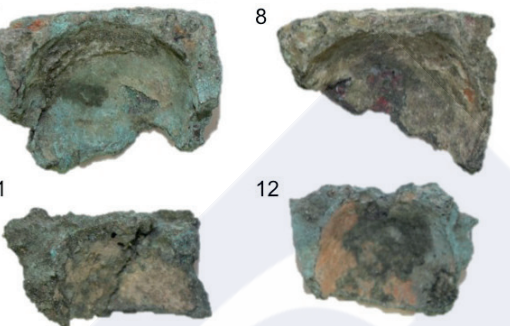

14
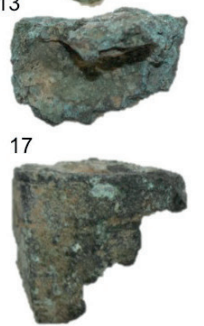

22

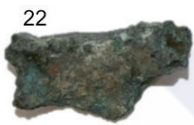

25
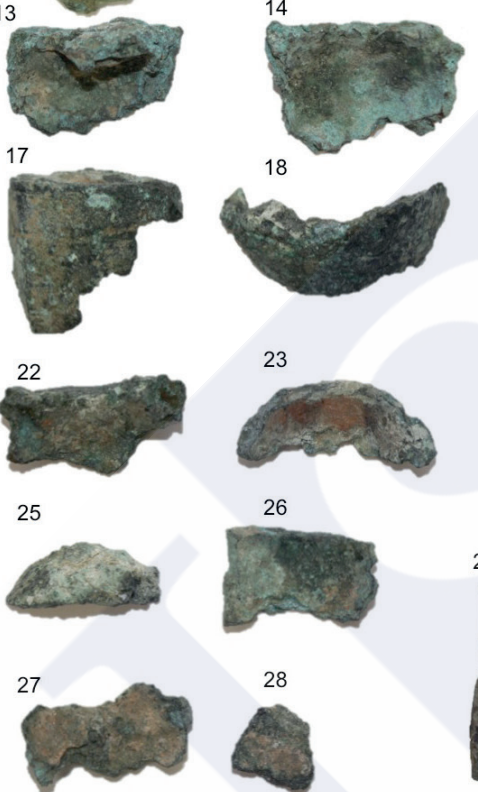

18
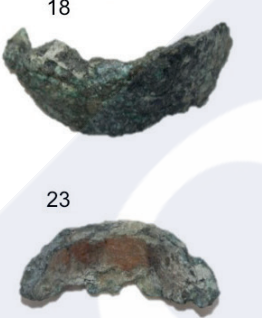

26
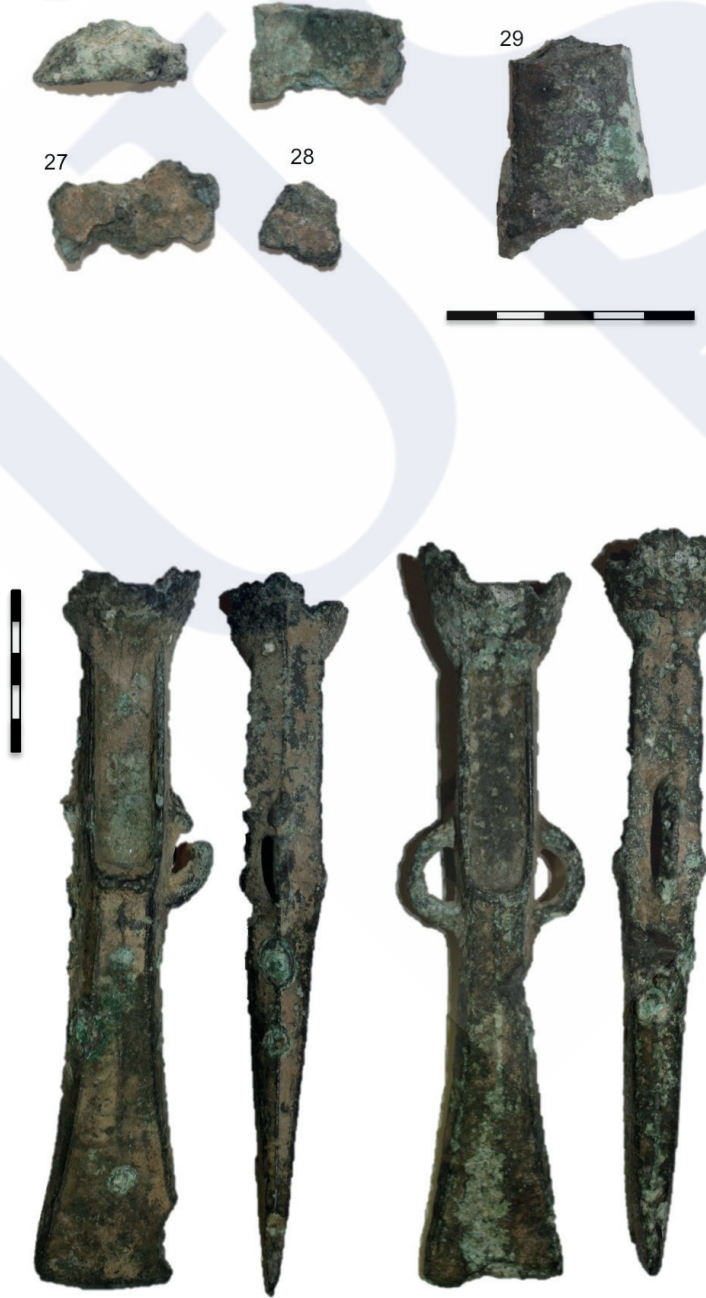
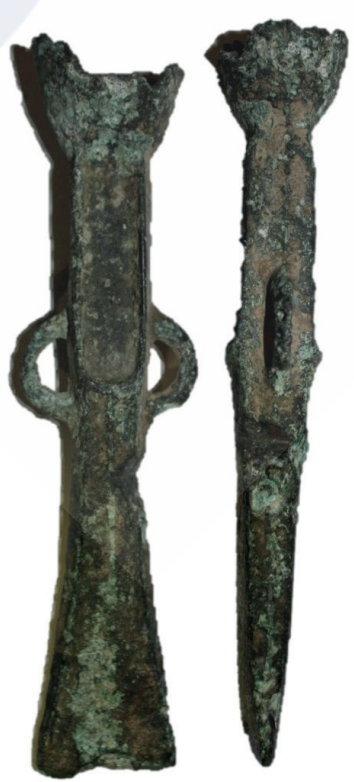

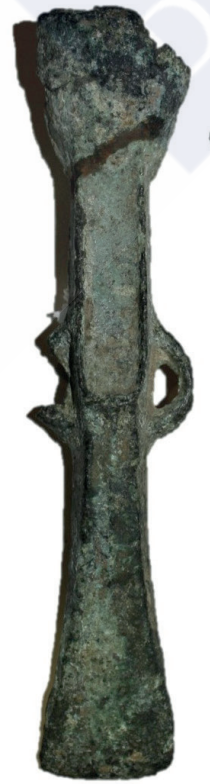

Figura 8. Carcasas de bronce pertenecientes a conos de fundición huecos con seğregación física del plomo en depósito en el Museo de Artes Decorativas de Viana do Castelo, eventualmente del depósito de Pereiras Pequenas.

Figura 9. Hachas expuestas en la Casa dos Nichos, en Viana do Castelo eventualmente del depósito de Pereiras Pequenas (número de inventario 2605). 
El hacha no. 1 de Maciel (2003:73) presenta rebabas de fundición, fundición deficiente con presencia de vacuolas y de burbujas, además de un desgaste en una de las extremidades del filo que el autor cree ser reciente. Tal y como infiere Viana (1939: 9), y por lo que se aprecia en los dibujos de Monteagudo (1977) con respecto a las formas y a las diferencias en el peso de los ejemplares (Tab. 1), resulta evidente que las hachas fueron fundidas en distintos moldes bivalvos.

\section{RESULTADOS E INTERPRETACIONES}

Según la interpretación de Viana (1938: 9) este conjunto de hachas responde a un depósito de fundidor en función de la clasificación establecida por Evans (1881: 457-458) que diferencia entre depósitos de fundidor y de mercader. De acuerdo con este autor, los primeros estaban compuestos por lingotes, objetos fracturados y usados, y los últimos se componían de objetos recién manufacturados y depositados en gran número. Aún teniendo en cuenta que la amortización de hachas responde a una variedad de prácticas culturales y socio-simbólicas que no pueden ser entendidas por modelos económicos modernos o contemporáneos, otros autores como Ruiz-Gálvez (2000: 275-276), Maciel (2003:74), Galán Domingo (2005: 471), Briard (1965: 2001) o Bradley (1990: 119) consideran que estos depósitos formados por hachas sin acabar (con rebabas y conos de fundición todavía presentes), depositadas en gran número, y compuestas por aleaciones ternarias, de cobre, estaño y plomo (lo que dificultaría su uso) podrían haber sido utilizadas como monedas primitivas.

R. Vilaça (2006: 23) también considera a estos depósitos formados por hachas con una gran cantidad de plomo (lo que las convierte en poco eficaces para su uso), desde una perspectiva ritual o cultual, pudiendo entenderse como ofrendas a los dioses, o deposiciones votivas, quizás resultado de la acumulación social de riqueza.

El conjunto monotipológico ${ }^{10}$ de Pereiras Pequenas/Rexio, formado integramente por hachas de tope con dos anillas laterales, constituye una categoría deposicional ampliamente documentada en el Bronce Final del Noroeste de la Península Ibérica. Aunque la mayoría de estas deposiciones son muy modestas (normalmente formadas por dos o tres ejemplares), y puedan aparecer asociados a afloramientos, o en el subsuelo, casi todos los conjuntos de mayor entidad, han sido tradicionalmente localizados en el subsuelo y mayoritariamente mostrando evidencias del proceso de fundición, con hachas con rebabas y conos de fundición presentes, lo que demuestra que nunca fueron usadas. Este es el caso de los depósitos de Abelheira, São Martinho de Bougado, Trofa (SARMENTO 1888: 157-158; SAMPAIO 2014), del Monte da Senhora do Pinheiro/Monte da Senhora Aparecida, Felgueiras (MONTEAGUDO 1977: 166, 170; SAMPAIO 2014), Faldejães, Arcozelo, Ponte de Lima (NEVES 1987 y datos inéditos), Aveleira, Vilar de Mouros, Caminha (inédito), Gingleta, Verdoejo, Valença (FORTES 1905-1908a y datos inéditos);

10 Entendido como un depósito compuesto enteramente por hachas, incluyendo tipos diferentes, y característico de varias regiones europeas, mayoritariamente situadas en la fachada atlántica (Bottaini 2012: 282). 
Carpinteira, Melgaço (FORTES 1905-1908b), Cabeiras, Arbo (CARBALLO ARCEO \& REY CASTIÑEIRA 2014), para citar solo los depósitos de la fachada más occidental entre las cuencas del Ave y del Miño ${ }^{11}$.

Por sus características morfológicas, se podría inferir que las hachas en estos depósitos han sido fabricadas localmente en distintos centros de producción, o en el mismo con distintos moldes. Los restos del proceso de fundición, en la forma de rebabas, conos de fundición y filos embotados, evidencias de su pobre ejecución, podrían indicar que estas hachas fueron manufacturadas por artesanos?/ metalurgos? poco cualificados, o quizás podrían obedecer a actos deliberados destinados a la producción de objetos de naturaleza ritual, debido a sus pobres cualidades mecánicas (FONTIJN 2002: 160), dado que resulta evidente que nunca fueron utilizadas, y sin embargo fueron producidas en grandes cantidades para ser luego amortizadas.

Es curioso verificar, en términos del contexto espacial, que el depósito de Pereiras Pequenas, tal como todos los aquí citados, se localiza en las cercanías de cursos de agua, en zonas posiblemente ricas en recursos mineros de casiterita y en un lugar natural de paso y de encrucijada de caminos, entre el sur y el norte, es decir, entre las cuencas del Neiva y del Lima, o bien entre el océano y el interior (Fig. 10).

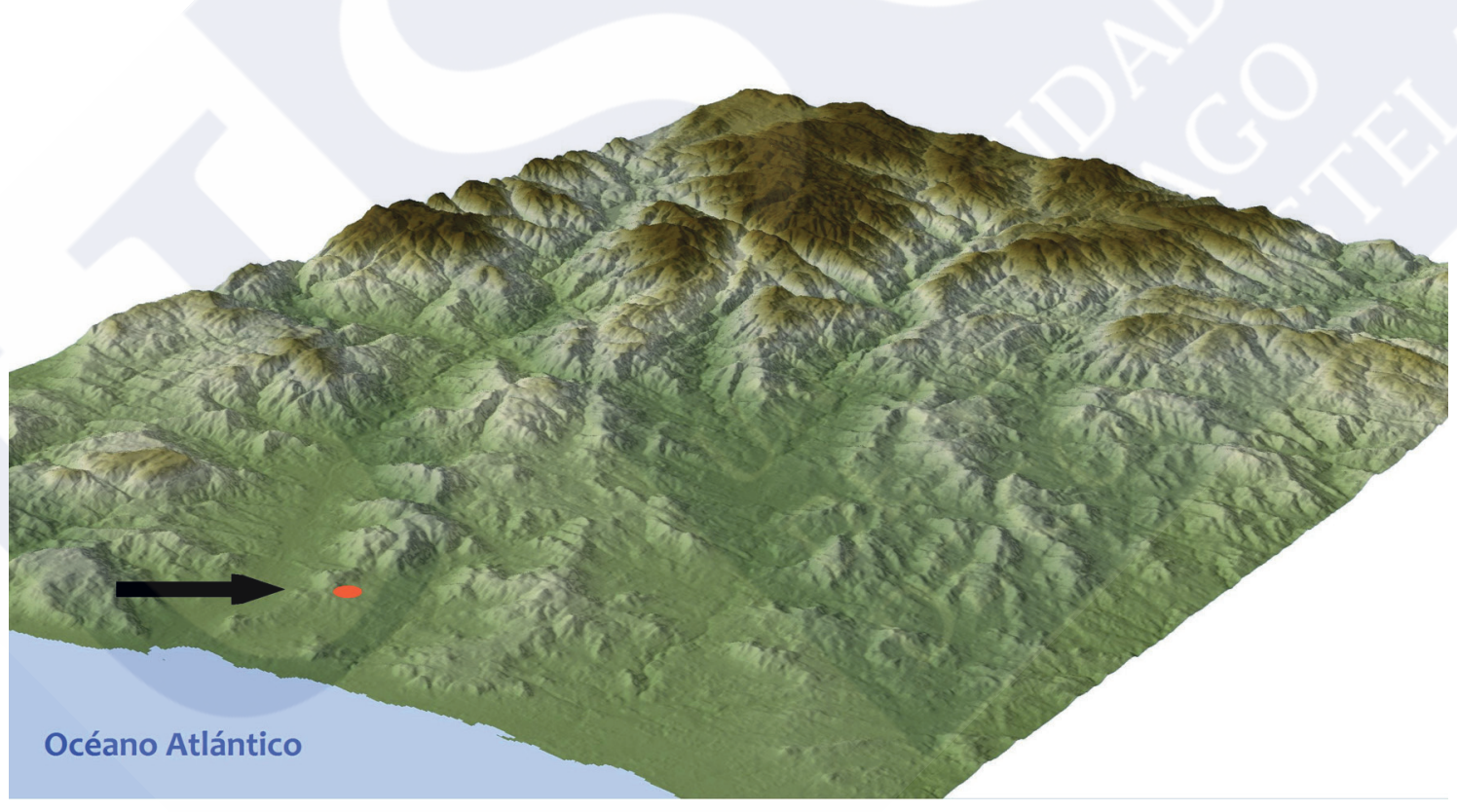

Figura 10. Modelo digital del terreno con la localización del depósito de Pereiras Pequenas, Vila de Punhe, en el estuario del rio Neiva y en la base de los Montes del Coturinho y Roques, en las proximidades del paso natural hacia el valle del Lima, al norte.

11 Existen otros depósitos con gran cantidad de hachas en el Noroeste de la Península Ibérica, especialmente otros dos conjuntos con más de cien ejemplares. Uno de ellos es el depósito de Samieira, Ladróns, Poio, Pontevedra, con 170 ó 175 hachas de tope con dos anillas laterales de las que solamente se conservan 152. Según García Bellido (1946) y Sierra Rodríguez et al. (1984) fue descubierto por un agricultor en 1946, a escasos metros del mar. Este conjunto difiere del depósito de Pereiras Pequenas por el hecho de que las hachas no presentan conos de fundición, aunque si muestran todas ellas las rebabas de los moldes (GARCíA BELLIDO 1946: 265). El segundo es el depósito de San Xoan da Lagoa, Pastoriza, Lugo, con 120 hachas de tope con dos anillas laterales, de los que solamente se conservó un hacha, dado que fueron todas fundidas poco tiempo después de su descubrimiento (OBERMAIER 1923: 28). Aunque de este último no se conoce el contexto del hallazóo ni el ejemplar en cuestión. 
Se trata de un lugar relativamente abrigado y alejado de cualquier poblado del Bronce Final conocido para la cuenca del Neiva ${ }^{12}$. Por estos motivos creemos que la deposición de estas hachas, de gran valor simbólico, podría ser resultado de una ceremonia colectiva de gran amplitud, que celebraría o tendría una acción profiláctica sobre una encrucijada importante de caminos (lugares normalmente peligrosos y poblados de seres sobrenaturales en el imaginario popular de las poblaciones del Norte de Portugal) ${ }^{13}$. La importancia de este lugar se puede relacionar con el hecho de que constituya una zona liminar entre el interior y la desembocadura del valle del Neiva, en la base de montes que, por lo menos desde el Calcolítico, fueron celebrados con arte rupestre, como es el caso del Monte do Coturinho y el de Roques, con vistas al lugar de hallazgo por el Norte ${ }^{14}$.

Esta categoría deposicional ha sido ampliamente reproducida en vastas zonas de la Europa Atlántica, particularmente en zonas con riqueza mineral, principalmente estannífera. ¿Porque habrían de fabricar los metalurgos hachas afuncionales en zonas tan separadas?, ¿Porque nunca fueron recuperadas en la Edad del Bronce?

Independientemente de una respuesta más funcionalista o simbólica, la Edad del Bronce Final coincide con el apogeo de las producciones metálicas, en la que los enormes depósitos amortizados en este período constituyen, también, una evidencia de las grandes producciones de metal (BRIARD 2001: 40). El metal recuperado es de igual forma indicativo de la enorme cantidad de metal que había en circulación.

\section{RECONOCIMIENTOS}

Este trabajo fue efectuado en el ámbito del proyecto Espaços Naturais, Arquiteturas, Arte Rupestre e Deposições na Pré-história Recente da Fachada Ocidental do Centro e Norte Português: das Ações aos Significados - ENARDAS (PTDC/HIS-ARQ/112983/2009), financiado por el Programa Operacional Temático Factores de Competitividad (COMPETE) y coparticipado por el Fondo Comunitario Europeo FEDER, en el cual se inscribe la tesis de doctorado de Alexandre Manteiga, titulada “Depósitos de la Edad del Bronce de la Fachada Occidental del Noroeste de Iberia entre las Cuencas del Vouga y del Ulla: Contextos e Interpretaciones”. Los autores agradecen, también, a Emílio Abad-Vidal la base cartográfica de la fig. 9, al Sr. José Gonçalo Meira Alves, natural de Arques, Vila de Punhe, y al Padre Alípio Rodrigues Torres, párroco de Vila de Punhe, las informaciones prestadas.

12 Sobre el poblamiento de la Edad del Bronce de la Cuenca del Neiva se debe consultar a Maciel (2003).

13 Según diversas leyendas que han sido recogidas por uno de nosotros (AMSB), incluyendo la sierra de Santa Luzia, que se encuentra a pocos kilómetros hacia el norte.

14 Hay que destacar que estos montes aún son significativos para las poblaciones a través de la memoria popular. En la calle da Portela, muy cerca del lugar de hallazơo del depósito metálico que nos ocupa recogimos varias leyendas asociadas al Alto do Coturinho. Una de ellas lo asocia a San Silvestre, que, desde ahí, habría lanzado su bastón por dos veces, hacia atrás. La primera cayó en el río (Lima?) y la segunda se clavó en Cardielos, Viana do Castelo, lo que marcaría el emplazamiento de la capilla que Ileva su nombre. También se encuentra en el mismo lugar un podomorfo que los vecinos vinculan a las pisadas de una oveja/ cabra. Otros señalan la presencia de pozas, y agujeros, que vinculan a casas de mouras comunicados con el río Neiva. 


\section{Bibliografía}

ABREU, A.A.; ALMEIDA, C.A.B. 1988. Carta Arqueológica de Viana do Castelo. Viana do Castelo: Câmara Municipal (Policopiado).

AZEVEDO, P.A. 1897. Extractos archeologicos das "Memorias Parochiaes de 1758", O Arqueólogo Português, 2: 177-192; 262-264.

BOTTAINI, C.M. 2012. Depósitos metálicos no Bronze Final (Sécs. XIII-VII A.C.) do Centro e Norte de Potugal. Aspectos sociais e Arqueometalúrgicos. Coimbra: Faculdade de Letras da Universidade de Coimbra (Tese de Doutoramento - policopiada).

BRADLEY, R. 1990. The Passage of Arms. An archaeological analysis of prehistoric hoards and votive deposits. Cambridge: University Press.

BRIARD, J. 1965. Les dépôts Bretons et l'Âge du bronze Atlantique. Rennes: Travaux du Laboratoire d'Anthropologie Préhistorique. Faculté des Sciences de Rennes.

BRIARD, J. 2001. Les objets paléomonétaires de l'Europe atlantique protohistorique. Revue Numismatique, 6 (157): 37-50.

CARBALLO ARCEO, X.; REY CASTIÑNEIRA, J. 2014. The palstaves hoard of Cabeiras, Arbo (Galicia), in the context of the lower course of the Minho basin. En A.M.S. Bettencourt, B. Comendador Rey, H.S. Sampaio \& E. Sá (eds.). Corpos e metais na fachada atlântica da Ibéria. Do Neolítico à Idade do Bronze. Braga: CITCEM, APEQ. Associação Portuguesa para o Estudo do Quaternário, 103-120.

COMENDADOR REY, B.; BETTENCOURT, A.M.S.; MANTEIGA BREA, A. 2013. Projeto ENARDAS: Informe sobre el conjunto de hachas y artefactos de bronce existentes en el Museo de Artes Decorativas de Viana do Castelo, Casa dos Nichos (CNNA) y Gabinete de Arqueología da Câmara Municipal de Viana do Castelo. Braga: Universidade do Minho (Relatório Técnico-Científico - Policopiado).

EVANS, J. 1881. The Ancient Bronze Implements, Weapons and Ornaments of Great Britain and Ireland. London: Longmans, Green \& Co.

FONTIJN, D.R. 2002. Sacrificial Landscapes. Cultural Biographies of Persons, Objects and 'Natural' Places in the Bronze Age of the Southern Netherlands. Leiden/Leuven: Peeters.

FORTES, J. 1905-1908a. Esconderijo morgeano de Ganfei (Valença). Portugalia, 2 (1-4): 661.

FORTES, J. 1905-1908b. Esconderijo morgeano da Carpinteira (Melgaço). Portugalia, 2 (1-4): 475.

GALÁN DOMINGO, E. 2005. Evolución, adaptación y resistencia. En torno a las formas de intercambio de las comunidades atlánticas en contacto con el mundo orientalizante. En S. Celestino Pérez, J. Jiménez Ávila (eds.). El periodo orientalizante. Madrid: Instituto Arqueología Mérida - CSIC, Vol. 1: 467-475.

GARCÍA BELLIDO, A. 1946. Un depósito excepcional de hachas de bronce hallado en Pontevedra. Archivo Español de Arqueología, 19: 263-265.

LÓPEZ CUEVILLAS, F.; BOUZA BREY, F. 1929. Os oestrimnios os saefes e a ofiolatría en Galiza. Nós, v. 2: 27-193.

MACIEL, T.D.P. 2003. O povoamento Prehistórico do Vale do Neiva. Viana do Castelo: Asociación Río Neiva.

MONTEAGUdO GARCÍA, L. 1977. Die Beile auf der Iberischen Halbinsel. München: Prähistoriche Bronzefunde IX, 6.

MONTERO, I., ROVIRA, S., DELIBES, G., FERNÁNDEZ-MANZANO, J., FERNANDEZ POSSE, M.D., HERRÁN, J.I., MARTÍN, C.; MAICAS, R. 2003. High leaded bronze in the Late Bronze Age metallurgy of the Iberian Peninsula. En, Archaeometallurgy in Europe. 24-26 Septiembre 2003. Milán. Proceedings, Vol. 2. Associacione Italiana di Metallurgia. Milano: 39-46.

NEVES, J.Q. 1987. Outro esconderijo morgeano en terras do Alto Minho. Arquivo do Alto Minho, 28 (3): 171-174.

OBERMAIER, H. 1923. Impresiones de un viaje prehistórico por Galicia. Boletín de la Comisión Provincial de Monumentos Históricos y Artísticos de Orense. 7 (149): 25-47. 
PEREIRA, F.A. 1903. Machados de duplo anel. O Archeologo Português, 1 (8): 132-136.

PINTO, R.S. 1928. Museu de Martins Sarmento. Revista de Guimarães, 38 (3-4): 192-196.

PINTO, R.S. 1933a. Activité minière et metallurgique pendant l'Age du Bronze en Portugal, Anais da Faculdade de Ciências do Porto, 18 (2): 77-85.

PINTO, R.S. 1933b. Explotaciones mineras de la Edad del Bronce en Portugal, Investigación y Progeso, 7 (6):177-181.

REIS, A.P.M. 1978. Romanização do Concelho de Ponte de Lima. Ponte de Lima.

ROVIRA, S.; GÓMEZ RAMOS, P. 2003. Las primeras etapas metalúrgicas en la Península Ibérica: III. Madrid: Estudios metalográficos.

RUÍZ-GÁLVEZ PRIEGO, M. 2000. Weight systems and Exchange networks in Bronze Age Europe. En C. Pare (ed.). Metals Make The World Go Round. Oxford: Oxbow Books, 267-279.

SAMPAIO, H.A. 2014. A Idade do Bronze na bacia do Ave (Noroeste de Portugal). Braga: Universidade do Minho (Tese de doutoramento - policopiada).

SARMENTO, F.M. 1888. Antigualhas. Revista de Guimarães, 5 (4):157-163.

SIERRA RODRIGUEZ, J.C.; VAZQUEZ VAAMONDE, A.J.; LUIS, L.; FERREIRA, S. 1984. El Depósito del Bronce Final de Samieira. Investigacion Arqueoanalitica y Experimental. Boletín Avriense Anexo 2. Ourense: Museo Arqueolóxico Provincial.

TEIXEIRA, C. (1940). Molde de fundição para machados de bronze de duplo anel. Trabalhos da Sociedade Portuguesa de Antropologia e Etnologia, 9: 3-8.

TEIXEIRA, C.; MEDEIROS, A.C.; ALVES, C.A.M.; MOREIRA, M.M. 1969. Carta Geológica de Portugal na Escala de 1/50.ooo. Notícia Explicativa da Folha 5-C - Barcelos, Lisboa: Serviços Geológicos de Portugal.

TEIXEIRA, C.; MEDEIROS, A.C.; COELHO, A.P. 1972. Carta Geológica de Portugal na Escala de 1/50.ooo. Notícia Explicativa da Folha 5-A - Viana do Castelo, Lisboa: Serviços Geológicos de Portugal.

TEIXEIRA, C.; MEDEIROS, A.C.; LOPES, J.T. 1975. Carta Geológica de Portugal na Escala de 1/50.ooo. Notícia Explicativa da Folha 5-B - Ponte da Barca, Lisboa: Serviços Geológicos de Portugal.

TORRES, A.R. 2001. Vila de Punhe - Das Origens à Actualidade. Braga: Junta de Freguesia de Vila de Punhe.

VÁZQUEZ SEIJAS, M. 1953. Hachas de bronce de doble anillo. Boletín da Comisión de Monumentos Histórico, Artísticos de Lugo, t. V., 9: 208-214.

VEIGA, S.P.M.E. 1891. Antiguidades Monumentaes do Algarve: Tempos Prehistoricos. Vol. IV. Lisboa: Imprensa Nacional.

VIANA, T.S. 1938. Um esconderijo de fundidor. Revista do Alto Minho 1: 7-9.

VIEIRA, J.A. 1886. O Minho Pitoresco. Vol. 1. Lisboa.

VILAÇA, R. 2006. Depósitos de Bronze do Território Português. Um debate em aberto. O Arqueólogo Português, série III, 24: 9-150. 